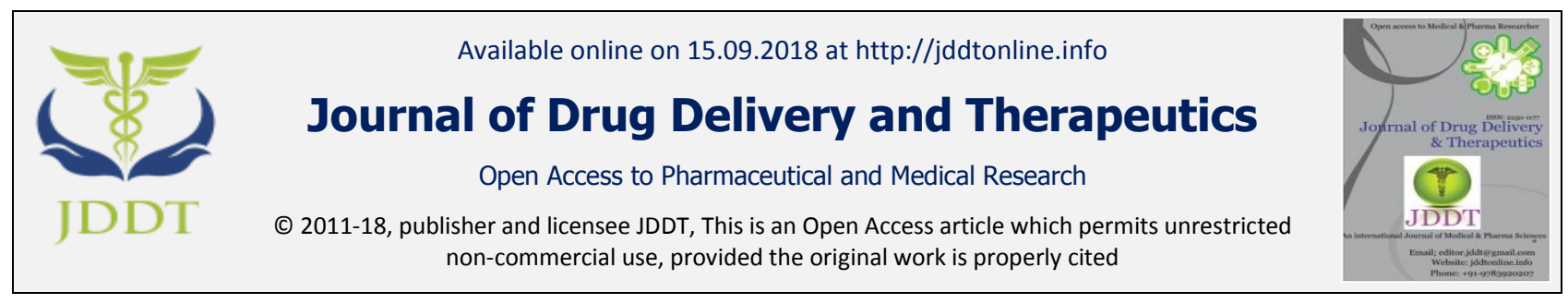

Open $\odot$ Access

Review Article

\title{
A GLOBAL CONCERN ON ZIKA VIRUS: TRANSMISSION, DIAGNOSIS, PREVENTION, AND TREATMENT
}

\author{
Nikhil Kushwaha $^{1^{*}}$, Vipin Kesharwani1 ${ }^{1}$, Pankaj Kumar Jaiswal ${ }^{2}$ \\ ${ }^{1}$ Chandra Shekhar Singh College of Pharmacy, Koilaha, Puramufti, Kaushambi, (U.P) India \\ ${ }^{2}$ Department of Pharmaceutical Science, Dibrugarh University, Dibrugarh Assam-786004, India
}

\begin{abstract}
Zika virus is a mosquito-transmitted flavivirus belongs to family Flaviviridae which becomes the focus of an ongoing pandemic and public health emergency all around the world. Zika virus has two lineages African and Asian. Mosquito-borne flavivirus is thought to replicate initially in dendritic cell and then spread to lymph nodes and then to the bloodstream. Zika virus was initially recognized in Uganda in 1947 in Monkeys through a method that observed yellow fever. It was later distinguished in people in 1952 in Uganda and the United Republic of Tanzania. The explosions of the zika virus disease have been recorded in Africa, The Americas, Asia, and The Pacific. Gillian-Berre syndrome and congenital malformation (microcephaly) suspected to be linked with Zika virus. The virus can only be confirmed through laboratory test on blood or other body fluids, such as urine, saliva or semen. No specific antiviral treatment for Zika virus disease exists. Treatment is aimed at relieving symptoms with rest, fluid and medications. WHO/PAHO encourages the countries to establish and maintain Zika Virus infections, detection, clinical management and community assurances strategies to reduce transmission of the virus. The future of Zika Virus spreading to other parts of the world is still unknown.
\end{abstract}

Keywords: Zika Virus, flavivirus, Mosquito, Vaccine, Treatment, Microcephaly, WHO/PAHO.

Article Info: Received 06 Aug, 2018; Review Completed 09 Sep 2018; Accepted 10 Sep 2018; Available online 15 Sep 2018

\section{Cite this article as:}

Kushwaha N, Kesharwani V, Jaiswal PK, A Global Concern on Zika Virus: Transmission, Diagnosis, Prevention, and Treatment, Journal of Drug Delivery and Therapeutics. 2018; 8(5):136-140

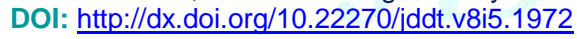

*Address for Correspondence:

Nikhil Kushwaha, Chandra Shekhar Singh College Of Pharmacy, Koilaha, Puramufti, Kaushambi, (U.P) India

\section{INTRODUCTION}

Zika virus is an arbovirus (arthropod-borne virus). It is a member of the Flaviviridae family, genus flavivirus, which includes dengue, yellow fever, and West Nile viruses. It was first identified in the zika near Kampala, Uganda in rhesus macaques in $1947^{1}$. Zika virus is an icosahedral, enveloped, single-stranded positive-sense RNA virus with the nonsegmental genome. Virus structure is $40 \mathrm{~nm}$ in diameter, with a lipid envelope coated with dense projections that consist of a membrane and enveloped glycoprotein and a dense inner core 2. Zika virus is a single-stranded RNA virus with two major lineages: Asian and Africa ${ }^{3,4}$. In Africa, Zika virus is thought to have been largely maintained in a cycle involving transmission between non-human primates (such as monkeys and apes) and mosquitoes, with human as occasional unintentional hosts ${ }^{5,6}$. In areas outside Africa, however, humans have probably become the main host ${ }^{7}$. Before November $2015^{8}$ zika virus was a quite unknown infectious agent, generating least attention compared to the current year's communicable disease like the MERS corona virus, influenza, and Ebola. The symptoms include a rash, fever, joint pain, red eyes, muscle pain, vomiting, and headaches. Management of ZIKV infected patients is easy as there is no zika a specific therapeutic or vaccine available because of it is mild and treatable symptoms. But now these two factors which have to boost the Zika virus to an unusual position of fame. The mildness of the symptoms and low incidence have allowed this virus to slip below the attention of people ${ }^{9}$. 

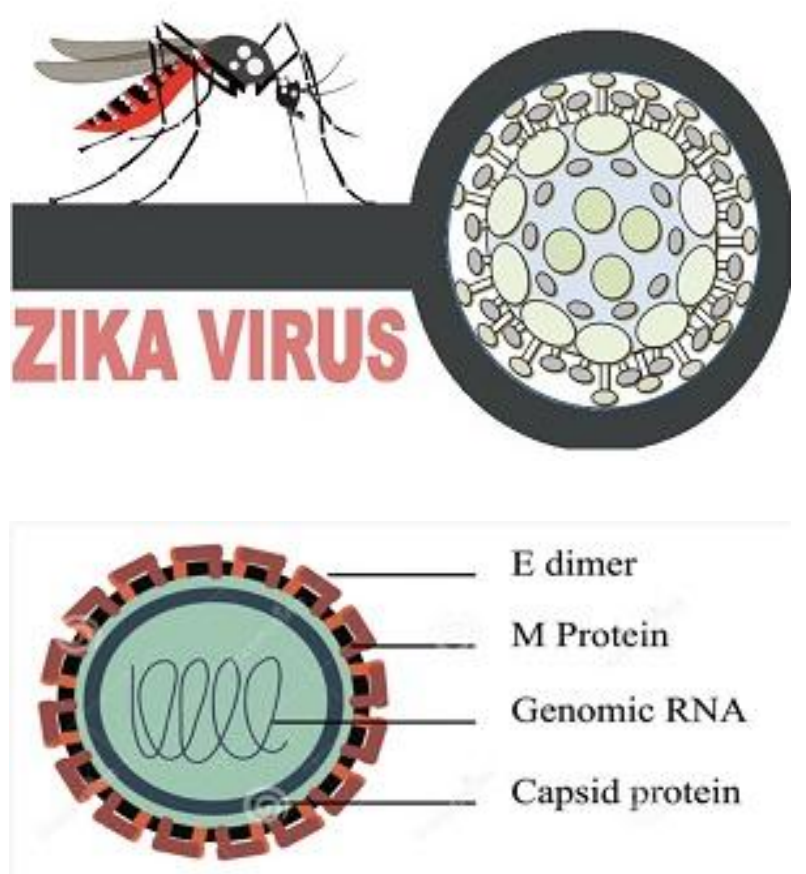

Figure 1: Schematic Diagram of Zika Virus and an Internal component of the virus

\section{EPIDEMIOLOGY}

Zika virus was first isolated in April 1947 from a rhesus macaque monkey, which was used as a research animal by a scientist of the Yellow Fever Research Institute, located in Zika forest, near Lake Victoria Uganda. This scientist named this filterable transmissible agent "Zika Virus" in $1948^{10}$. In January 1948, this virus was isolated from Aedes Africanus at the same site. The very first human cases were reported in 1952 in Tanzania and Uganda. In 2007 an outbreak caused by a strain of Asian lineage occurred on the ia island of Yap, an island state of the Federated States of Micronesia. Estimated cases affected in this and subsequent outbreak to date is probably imprecise, given the incomplete laboratory confirmation and similarities in clinical presentation of Zika virus with other arbovirus infections presents throughout the tropics. In Yap, 49 confirmed and 59 probable cases (defined according to strict serological criteria or RNA detection by reverse transcriptionpolymerase chain reaction) were defined over a fourmonth period. Brazil is the most adversely affected country of the Latin American region with approximately 500,000-1,500,000 Zika Virus cases since March $2015^{11}$. Numerous cases of the dengue-like syndrome in Natal, in the state of Rio Grande do Norte, Brazil, were confirmed as Zika Virus infection, which was diagnosed using reverse transcription polymerase chain reaction (RT-PCR). Afterward, numerous outbreaks occurred in the different state of Brazil, Colombia, Mexico, Guatemala, Paraguay, El Salvador, Bonaire, Samoa, Trinidad and Tobago, Aruba, Sint Marteen, Argentina, Venezuela, etc. and subsequently reached the USA. A close phylogenetic relationship between Asian an Oceanic strain and South America strains of Zika Virus may be associated with the introduction of Zika Virus in Brazil by the participants from the oceanic countries for the Va'a World Sprint Championship or Asian Travelers during the FIFA World Cup 12,13,14,15.

\section{TRANSMISSION}

In 1947, Scientist isolates the Zika virus in samples taken from a sentinel rhesus monkey in Zika forest, Uganda. The first proof of viral infection was reported when a researcher in Uganda who fell ill while working with Zika strains isolated from mosquitoes. This discovered that Zika virus can spread to humans. Later it was reported in a few African nations, the Pacific, and components of Asia and Yap Island, Micronesia in 2007. In October of 2013, Zika reaches French Polynesia and spreading to near islands like Cook Island and Easter Island. The virus gradually spread to Brazil by May $2015^{16,17}$. Zika virus continues to spread at an extraordinary. Currently, it is found in 14 Brazilian states and 10 countries in South and Central America, including Mexico and most recently Panama. Along with Dengue and Chikungunya, which are also transmitted by the Aedes aegypti mosquito. Zika virus is most likely maintained in a sylvatic cycle that includes non-human primates and mosquitoes with cyclic epizootics among monkeys in Uganda. Another emerging fact of the zoonosis has been the probable transmission through bites of monkeys and non-human primates. In the sylvatic transmission cycle, human possibly serves as incidental hosts; however, in areas without non-human primates, a human probably serve as primary intensification hosts ${ }^{18}$. Zika virus was detected in approximately $3 \%$ of asymptomatic blood donors during the French Polynesian outbreak suggesting that transmission might be possible through infected blood and blood products ${ }^{19}$. Evidence implies transplacental transmission and perinatal transmission during delivery, with Zika virus RNA being found in amniotic fluid and in paired blood samples taken from newborn infants and mothers ${ }^{20,21}$. Unintentional sexual transmission of Zika virus to the female partner and subsequently to the fetus may result in awful congenital anomalies among the newborns. Transmission of Zika virus from mother to infant can occur in utero or perinatally ${ }^{22,23}$. Transmission of Zika virus via breastfeeding has not yet been observed although the transmission of another flavivirus via this route has been describing previously 24,25 . The other suspected routes of Zika virus transmission include monkey bite, mucocutaneous exposure, organ transplantation or hemodialysis $26,27,28$. The risk of Zika virus infection among kidney recipient should also be considered if the donors are either residing in or returning from endemic regions, because the virus may be shed in the urine of the infected person for more than 30 days ${ }^{29,30}$. Due to occasional detection of viral RNA in a saliva sample and nasopharyngeal swab, it is still unknown that Zika virus could be spread through respiratory droplets ${ }^{31}$. 


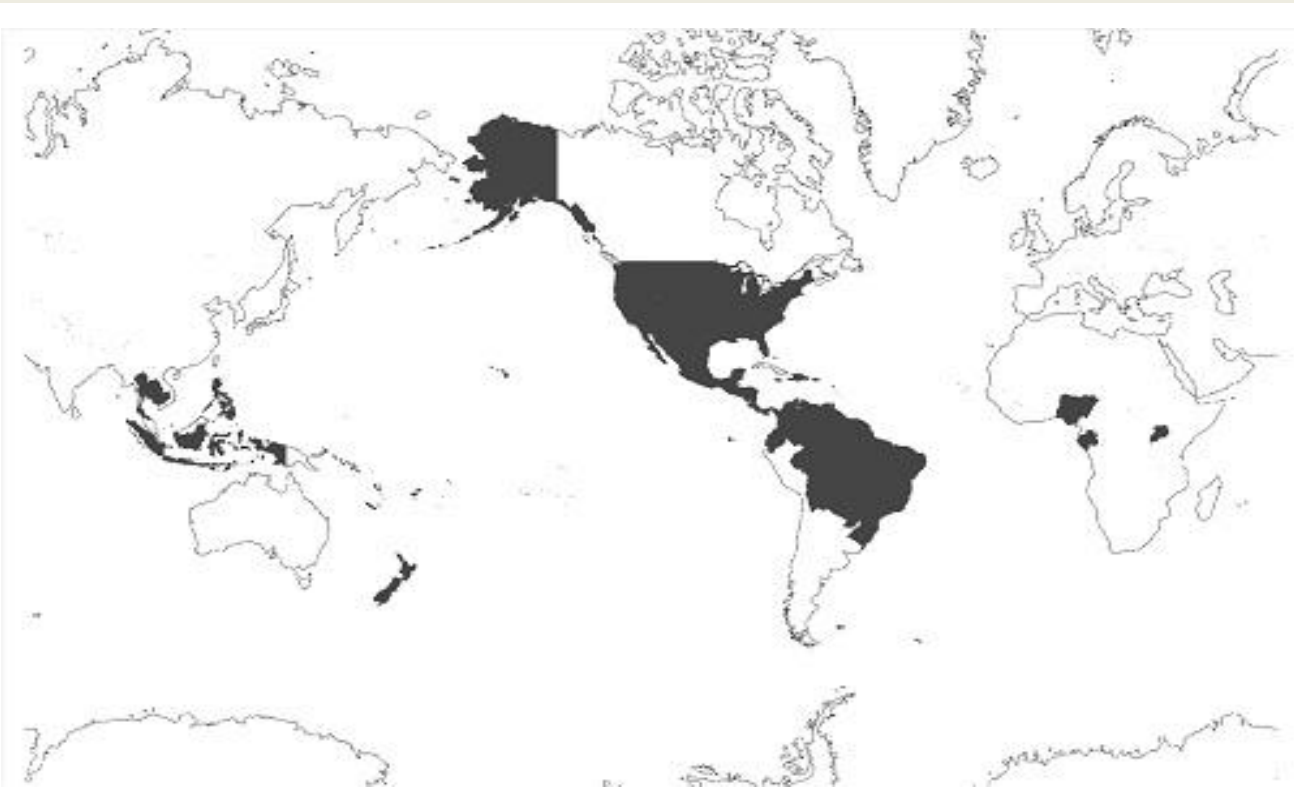

Figure 2: All countries and regions reporting laboratory-confirmed autochthonous Zika virus. (http://wwwnc.cdc.gov/EID/article/22/7/15-1990-Techapp1.pdf)

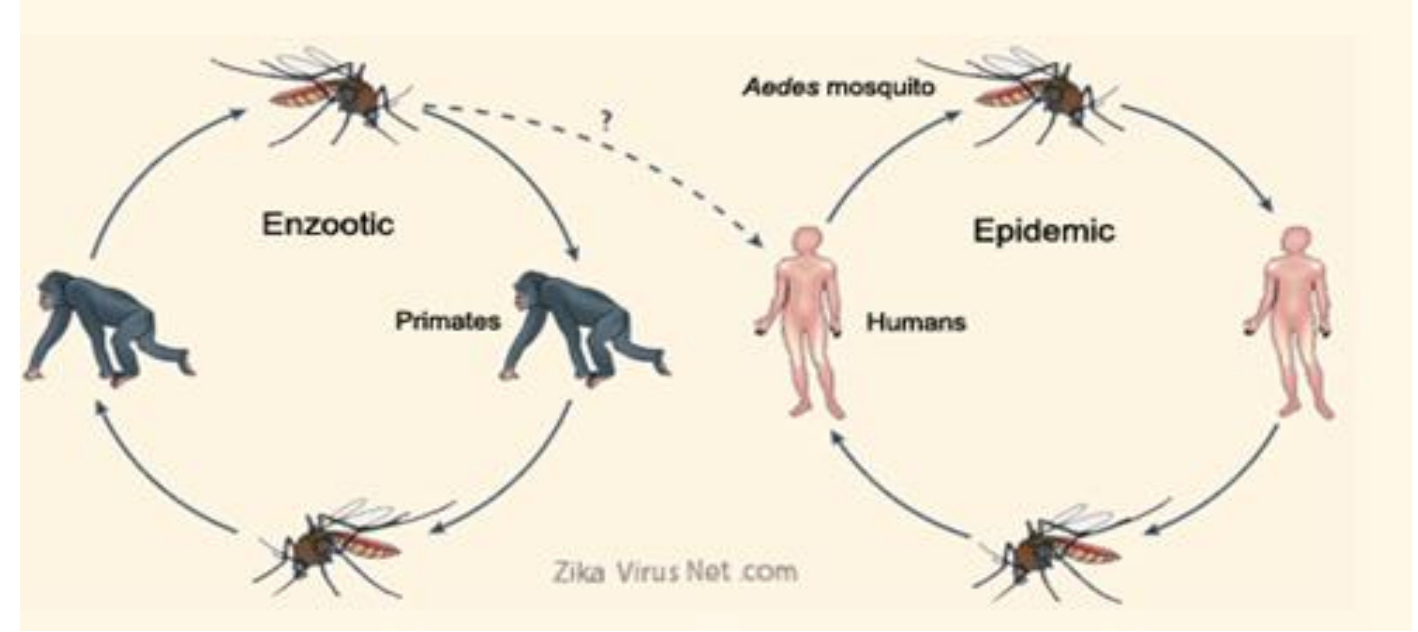

Figure 3: Transmission of Zika virus, Source:

\section{PATHOGENESIS}

Pathogenesis of Zika virus is almost unknown; however, it is found that mosquito-borne flaviviruses initially replicate in dendritic cells close to the inoculation site and then spread to lymph node and the blood. Although flaviviral replication is found to occur in cellular cytoplasm, studies suggest that Zika virus antigen can be found in the nucleus of the infected cells. Moreover, the infectious Zika virus has been detected in human blood before the beginning of symptoms. After the replication, zika virus may distribute from the lymphatic and bloodstream to infect other organs of the body such as the myocardium, central nervous system, skeletal muscles and to the fetus. The virus replication in astroglial cells and neurons in the brain of infected suckling mice results in neuronal degeneration, cellular infiltration, and alleviation in the brain. Furthermore, the evidence of inflammation is found in the myocardium and skeletal muscles in the infected mice. The neurotropism and tenacity of Zika virus may explain neurological complications such as microcephaly in congenital Zika virus infection ${ }^{32}$.

\section{DIAGNOSIS}

Laboratory approval is necessary for the diagnosis of Zika infection considering that there is no pathognomonic presentation that differentiates Zika fever from other infection as well as congenital Zika virus infection from other etiologies of congenital abnormalities. There are two types of diagnosis for Zika infection. The first type includes the detection of the virus or viral particles RT-PCR, immunoassay and virus isolation have been invented to identify Zika virus RNA, viral proteins and live virus respectively. The second type of diagnosis is based on the detection of antibodies 31,33 . The cross-reactivity of antibodies between flaviviruses confines applies to serology ${ }^{34}$.

\section{Direct Viral Diagnosis}

Zika virus infection can be diagnosed primarily by RTPCR. The viremic period is believed to be small, as the virus can be detected in the blood from day 0 to 4 after the onset of symptoms. The time required for the recognition of viral RNA in the blood may also depend on the viral load during the acute phase of the disease because viremia decreases over time. A negative PCR 
result in blood collected 5-7 days after the onset of symptoms does not exclude the flavivirus infection. Therefore serological testing should be considered ${ }^{35}$.

\section{Serological Diagnosis}

Clinical signs and symptoms of Zika virus infection are non-specific, therefore, requiring laboratory examinations for differential diagnosis. Serologic test (i.e., enzyme-linked immunosorbent assay or immunofluorescence assays) is used for detection of ZIKV IgM antibodies from day 4 to 5 after the onset of symptoms. In general, the time duration for which the specific IgM antibodies for flavivirus remain detectable is 2-3 months, but sometimes for a longer period of time, while the specific $\mathrm{IgG}$ antibodies remain detectable for several months. At present, there is no validated commercial assay for Zika virus serological

\section{ZIKA VIRUS DRUGS}

Several research teams of scientists are in competition to develop a vaccine for the Zika virus ${ }^{37}$. These researchers first screened 774 drugs and eventually limit them to 24 drugs that showed some potential to block Zika from infecting cells ${ }^{38,39,40}$. An antibiotic like Duramycin was suggested for Zika virus, which decreases Zika's ability to infect cells. The scientist will continue to work on vaccine development even when drugs that stop Zika infections are identified ${ }^{41}$.

\section{VACCINE DELIVERY}

The Inovio ZIka product called GLS-5700 is called DNA vaccine. In that vaccine, DNA gets coded to yield the protein that encircles the Zika virus ${ }^{42}$. The site of the injection is damaged with a device that delivers a short electrical pulse that guides the DNA into cells through a process called electroporation. The cell then instructs the immune system to see the Zika virus as a foreign invader which needs to be attacked, producing antibodies to fight against it ${ }^{43,44}$.

\section{PREVENTION}

The main vectors involved in the spread and transmission of dengue, chikungunya, and Zika are a wide range of Aedes mosquitoes. Therefore, a preventive measure begins with strategies intended to

\section{REFERENCES}

1. Dick GW, Kitchen SF, Haddow AJ, Zika virus: Isolations and serological specificity. TransRSocTropMedHyg, 1952; 46:509-520. doi:10.1016/0035-9203(52)90042- 4. 12995440.

2. Konda S, Dayawansa S, Huang J, The Evolution and Challenge of the Zika virus and its Uncharted Territory in the Neurological Realm, J Neuroinfect Dis 2016; 7:215.

3. Haddow AD, Schuh AJ, Yasuda CY, Genetic characterization of Zika virus strains: geographic expansion of the Asian lineage, PLoS Negl Trop Dis.2012 6:e1477. doi:10.1371/journal.pntd.0001477. 22389730.

4. Faye O, Freire CC, Iamarino A, Molecular evolution of Zika virus during its emergence in the 20(th) century, PLoS Negl Trop Dis2014, 8:e2636. doi:10.1371/journal.pntd. 0002636. 24421913.

5. Haddow AJ, Williams MC, Woodall JP, Simpson DI, Goma LK. Twelve isolations of Zika virus from Aedes (Stegomyia) Africanus (Theobald) taken in and above a Uganda Forest, Bull World Health Organ, 1964; 31:57-69.14230895. diagnosis. Therefore, serological confirmation should be performed in a laboratory with expertise in discriminating flavivirus.

\section{TREATMENT}

Zika virus illness is generally mild in nature, requiring no specific treatment. Infected patients should increase their fluid intake and rest for longer durations. The only pharmacological treatment is acetaminophen, which is used to alleviate a headache, fever, and myalgia. Pruritus can be controlled with antihistamines, while fluid loss through vomiting and sweating should be corrected with adequate rehydration. Aspirin should not be used because of the risk of bleeding in patients with thrombocytopenia and development of Reye's syndrome in children under year age ${ }^{36}$.

avoid mosquito contact. These strategies include drainage of mosquito breeding site and use of insecticides and $\mathrm{N}$, N-diethyltoluamide (DEET) or picaridin containing insect repellents ${ }^{45}$. Regarding blood transfusion, testing of blood donors is suggested. When an outbreak happens, blood donation should be temporarily discontinued. In non-endemic places, using pre-donation questionnaire is helpful to screen donors who recently traveled to affected area and delay of blood donation from these donors until at least fourteen days after returning from affected places should be done. It is substantial to test donated organ of individuals who had a history of travel; to affected regions for Zika virus. Returned men travelers should persist to use condoms with a pregnant sex partner all over the time of pregnancy ${ }^{46}$.

\section{CONCLUSION}

Zika virus infection is generally caused by the mosquito bites (Aedes aegypti and some other species), especially, during the daytime. It was only a mild, treatable infection when it was first discovered in 1948. Africa was considered the most affected country followed by South and North America which reported Zika virus cases. WHO and other health officials advised people to stay home, prevent mosquito breeding and bite, abstain from traveling to Zika prone or affected the region and abstain from sexual intercourse even if so.

6. McCrae AW, Kirya BG Yellow fever and Zika virus epizootics and enzootics in Uganda, Trans R Soc Trop Med Hyg 1982; 76:552-62. doi:10.1016/0035-9203(82)90161-4. 6304948.

7. Duffy MR, Chen TH, Hancock WT, Zika virus outbreak on Yap Island, Federated States of Micronesia, N Engl J Med 2009; 360:2536-43. doi:10.1056/NEJMoa0805715. 19516034.

8. $\mathrm{Xu} \mathrm{Z,} \mathrm{MEKK3} \mathrm{coordinates} \mathrm{with} \mathrm{FBW7} \mathrm{to} \mathrm{regulate}$ microcephaly associated protein WDR62 and neurogenesis. 6th World Congress on Cell \& Stem Cell Research, Philadelphia. USA, 2016.

9. Weltman JK 2016. An Immuno-Bioinformatic Analysis of Zika virus (ZIKV) Envelope E Protein, J Med Microb Diagn, 2016; 5:228.

10. Hayes EB. Zika virus outside Africa. Emerg Infect Dis, 2009; 15(9):1347-50. 
11. Bogoch II, Brady OJ, Kraemer M, German M, Creatore MI, Kulkarni MA, Anticipating the international spread of Zika virus from Brazil, Lancet (London, England) 2016; 387:335-6.

12. Corsica F, Zika virus transmission from French Polynesia to Brazil, Emerg Infect Dis, 2015; 21:1887.

13. Enfissi A, Codrington J, Roosblad J, Kazanji M, Rousset D, Zika virus genome from the Americas, Lancet 2016; 387:2278. doi:10.1016/S0140-6736(16)00003-9.

14. Salvador FS, Fujita DM, Entry routes for Zika virus in Brazil after the 2014 world cup: new possibilities, Travel Med Infect Dis, 2016; 14:49-51. doi:10.1016/j.tmaid.2015.10.004.

15. Marcondes CB, Ximenes MDF, Zika virus in Brazil and the danger of infestation by Aedes (Stegomyia) mosquitoes, Rev Soc Bras Med Trop, 2016; 49:4-10. doi:10.1590/0037-86820220-2015.

16. Kushwah RS, Jain J, Sharma A, Bhatnagar RK, Subbarao SK, Co-Habitation and Concurrent Infection of Dengue and Chikungunya Viruses in Aedes Aegypti Field Populations from India, J Trop Dis, 2015; 4:194.

17. Adikari M, Perera C, Fernando M, Loeb M, Premawansa S Prevalence of Hypocalcemia and Its Potential Value as a Biochemical Marker in Patients with Severe Dengue Infection, J Trop Dis, 2015; 4:188.

18. Rodriguez-Morales AJ, Bandeira AC, Franco-Paredes C, The expanding spectrum of modes of transmission of Zika virus: a global concern, Ann Clin Microbiol Antimicrob, 2016; 15:13.

19. Musso D, Roche C, Robin E, Nhan T, Teissier A, CaoLormeau VM, Potential sexual transmission of Zika virus, Emerg Infect Dis, 2015; 21:359-61. doi:10.3201/eid2102.141363. 25625872.

20. Calvet G, Aguiar RS, Melo ASO, Detection and sequencing of Zika virus from amniotic fluid of fetuses with microcephaly in Brazil: a case study, Lancet Infect Dis, 2016; doi:10.1016/S1473-3099(16)00095-5.

21. Besnard M, Lastère S, Teissier A, Cao-Lormeau V, Musso D, Evidence of perinatal transmission of Zika virus, French Polynesia, Euro Surveill 2014; 19:20751. doi:10.2807/15607917.ES2014.19.13.20751. 24721538.

22. Hennessey M. Zika virus spreads to new areas - region of the Americas, MMWR Morb. Mortal.Wkly, 2016; 65:1031-1034.

23. Petersen EE, Erin Staples J, Meaney-Delman Dana, Fischer Marc, Ellington Sascha R, Callaghan William M, Interim guidelines for pregnant women during a Zika virus outbreakthe United States, MMWR Morb Mortal Wkly Rep, 2016; 65:30-33.

24. Barthel A, Gourinat A-C, Cazorla C, Joubert C, DupontRouzeyrol M, Descloux E. Breast milk as a possible route of vertical transmission of dengue virus, Clin Infect Dis, 2013; 57:415-417.

25. Hinckley AF, O’Leary DR, Hayes EB, Transmission of West Nile virus through human breast milk seems to be rare, Pediatrics, 2007; 119:666-671.

26. Chen LH, Wilson ME, Transmission of dengue virus without a mosquito vector: nosocomial mucocutaneous transmission and other routes of transmission, Clin Infect Dis, 2004; 39:56-60.

27. Leung GH, Baird RW, Druce J, Anstey, Zika virus infection in Australia following a monkey bite in Indonesia, Southeast Asian J Trop Med Public Health, 2015; 46:460-4.

28. Fonseca K, Meatherall B, Zarra D, Drebot M, MacDonald J, Pabbaraju K, First case of Zika virus infection in a returning
Canadian traveler, Am J Trop Med Hyg, 2014, 91:1035-1038. doi:10.4269/ajtmh.14-0151.

29. Kutsuna S, Kato Y, Takasaki T, Moi M, Kotaki A, Uemura H, Two cases of Zika fever imported from French Polynesia to Japan, Euro Surveill, 2014;19:20683.

30. Gourinat AC, Connor O, Calvez E, Goarant C, DupontRouzeyrol M, Detection of Zika virus in urine, Emerg Infect Dis, 2015; 21:84-6. doi:10.3201/eid2101.140894.

31. Musso D, Roche C, Nhan TX, Robin E, Teissier A, CaoLormeau VM, Detection of Zika virus in saliva, J Clin Virol Off Publ Pan Am Soc Clin Virol, 2015; 68:53-5. doi:10.1016/j.jcv.2015.04.021.

32. Chan JF, Choi GK, Yip CC, Cheng VC, Yuen KY, Zika fever and congenital Zika syndrome: an unexpected emerging arboviral disease, J Infect, 2016; 72(5):507-24.

33. Shan C, Xie X, Barrett ADT, Garcia-Blanco MA, Tesh RB, da Costa Vasconcelos PF, Zika virus: diagnosis, therapeutics, and vaccine, ACS Infect Dis, 2016; 2(3):170-2.

34. Mussoa D, Rocheb C, Nhana TX, Robina E, Teissierb A, CaoLormeaub V, Detection of Zika virus in saliva, J Clin Virol, 2015; 68:53-5.

35. Faye O, Freire CC, Iamarino A, Faye O, de Oliveira JV, Diallo $\mathrm{M}$, Molecular evolution of Zika virus during its emergence in the 20th century, PLoS Negl Trop Dis, 2014; 8(1):e2636.

36. European Centre for Disease Prevention and Control. Interim guidance for healthcare providers and Zika virus laboratory diagnosis. ECDC, Stockholm. 2016.

37. Chen LH, Hamer DH. Zika virus: rapid spread in the Western hemisphere, Ann Intern Med, 2016; 164:613-5. doi:10.7326/M16-0150.

38. Huy NT, Trieu HT, Okamoto K, Ninh TTH, Ha TTN, Proteomic Profile of Circulating Immune Complexes in Dengue Infected Patients, J Trop Dis, 2013; 1: 109.

39. Huu TN, Quang LC, Vu TQH, Forrat R, Lang, Safety and Immunogenicity of Recombinant, Live Attenuated Tetravalent Dengue Vaccine (CYD- TDV) in Healthy Vietnamese Adults and Children, J Vaccines Vaccine, 2012;3: 162.

40. Bernardo CN, Nogueira MCO, Aquino ÉP, Schmidtke S, Azeredo EL, With NMR Towards New Diagnostic Methods For Dengue, J Anal Bioanal Tech, 2012;3: 140.

41. Roberge LF, Chikungunya Virus (CHIKV): Coming to America, Biosafety, 2014; 3: e149.

42. Yaseen HM, Simon F, Deparis X, Marimoutou C, Estimation of Lasting Impact of a Chikungunya Outbreak in Reunion Island, Epidemiol, 2012;2:003.

43. Senanayake MP, Childhood Dengue: An Overview on Costof- Illness in Asia, Pediat Therapeut, 2014; 4:195.

44. Kannan S, Effect of Thyroxine on Mosquito Larvae during Winter Months in Dengue Prone Regions of India, Trop Med Surg, 2014; 2: 159.

45. Morales Borges RH, Dengue Virus: From Basics to New Technology in Testing \& Transfusion Safety, J Blood Disord Transfus, 2013; 4: 161.

46. Staples JE, Dziuban EJ, Fischer M, Cragan JD, Rasmussen SA, Cannon MJ, Interim guidelines for the evaluation and testing of infants with possible congenital Zika virus infectionUnited States, MMWR Morb Mortal Wkly Rep, 2016; 65:637. doi:10.15585/mmwr.mm6503e3. 